\title{
The Mobile Agility Framework: An Exploratory Study of Mobile Technology Enhancing Organizational Agility
}

\section{Vlad Krotov $^{1}$, Iris Junglas ${ }^{2}$ and Douglas Steel ${ }^{3}$}

\author{
${ }^{1}$ Abu Dhabi University, College of Business, Abu Dhabi, UAE, vlad.krotov@adu.ac.ae \\ ${ }^{2}$ Florida State University, College of Business, Tallahassee, FL, USA, ijunglas@cob.fsu.edu \\ ${ }^{3}$ University of Houston-Clear Lake, School of Business, Houston, TX, USA, steel@uhcl.edu \\ Received 14 December 2014; received in revised form 23 December 2014; accepted 29 December 2014
}

\begin{abstract}
Organizational agility is a key factor for survival and success in today's global, interconnected and turbulent business environment. Mobile technology, due to its anywhere, anytime characteristics, can be a promising tool for enhancing organizational agility. Yet there are no studies that guide organizations in leveraging mobile technology for improving speed and responsiveness to market needs. This paper attempts to fill this gap by exploring the question of how mobile technology can be used to enhance organizational agility. We use an exploratory research approach that analyzes archival data of 89 case studies describing contemporary applications of mobile technology within organizations. After developing a mobile agility framework and using it as our analytical lens, we examine each case to identify specific ways in which mobile technology is used to improve operational, customer, and partnering agility. The main contribution of this study is identification of emergent clusters of agility-enhancing mechanisms based on the benefits of mobile technology. The discovered benefits and mechanisms can guide organizations on improving their agility with the help of mobile technology. We also formulate research questions that should be addressed by future studies in order to produce a more comprehensive theoretical understanding of how mobile technology improves organizational agility.
\end{abstract}

Keywords: Agility, Mobile technology, Operational, Customer, Partnering, Ubiquity, Uniqueness 


\section{Introduction}

A turbulent, unpredictable, interconnected, fragile and increasingly global business environment is a defining characteristic of today's economic and social landscape [6], [11], [38], [40]. To survive and prosper in this environment, managers must turn to new strategies and managerial approaches [10]. One such strategy that was developed in response to the turbulent business environment is agility. Being agile can help organizations respond to challenges and opportunities in a timely manner [28] and improve organizational performance [39]. But to reach a desirable level of agility, one needs to understand the mechanisms of agility at work.

Often, people have an intuitive understanding of the term agility and the potential benefits of being agile. A literature search on the keyword agile returns a plethora of text from such areas as manufacturing, supply chain management, business strategy, military strategy, and even martial arts. In the field of Information Systems (IS) there are also some studies that theorize on how information technology (IT) can serve as an enabler of organizational agility [11], [15], [37], [39], [41]. But these works consider IT as an amorphous and all-encompassing entity and do not focus on specific types of IT that can contribute to agility. Yet an executive responsible for formulating and implementing organizational strategies needs exactly that- a focused set of recommendations on how a particular type of IT can be used to enable organizational agility.

Mobile technologies possess unique characteristics that can make them a valuable platform for building organizational agility. Moreover, devices and information systems using the capabilities of mobile technologies are becoming commonplace in organizations as employees are increasingly equipped with smartphones and mobile computers. Not only within the physical boundaries of an office but also when traveling, employees are able to wirelessly connect to a firm's network and stay informed and productive. Unique characteristics as well as their everincreasing adoption can make mobile technologies an important driver of organizational agility. Thus, the main goal of this study is to explore various ways in which mobile technologies can be used as an enabler of organizational agility. Since there is a lack of prior theorizing with respect to mobile technologies as part of an agility-centered, ITenabled strategic initiative, we use an exploratory research approach that employs multiple archival case studies to explore the question of how and why mobile technologies can enable organizational agility.

The rest of this paper is structured as follows. First, we review the concept of agility from the perspective of various business disciplines. After that, we focus on the perspective of agility within the IS discipline. More specifically, we review a framework proposed by Sambamurthy et al. [37] and use it as a conceptual foundation for explaining how IT can enable organizational agility. We argue that mobile technologies, as a subset of IT, possess unique characteristics that make them valuable for enabling organizational agility [9]. Based on this theoretical discussion, we develop a mobile agility framework that is based on the agility framework in [37] and the Junglas and Watson [15] u-construct framework. Using this new framework as our guiding lens, we examine and analyze archival data of 89 case studies in the area of mobile technology implementation. These cases are classified in appropriate dimensions of the mobile agility framework proposed by this study. We believe that the framework that we develop in this study as well as the specific examples of the use of mobile technology for enhancing agility can guide executives on formulating and implementing mobility-based strategies and provide tactics for improving organizational agility. Moreover, based on the content of the cases as well as existing literature on developments related to mobile technology, we formulate research questions that can extend our understanding of the role mobile technology can play in enabling organizational agility. At the end, we discuss limitations of this study that are largely a result of the data sample used and the employed data analysis method.

\section{Agility across Disciplines}

The notion of agility has been a research topic in several disciplines, including manufacturing, IT and organizational leadership. It is conceptualized as both the identification of and the reaction to change or opportunities. That is, agility is the "ability to detect and seize market opportunities with speed and surprise" [6] p. 238. The reaction component may have associated goals such as being a cost effective response [11] or a response with "ease, speed, and dexterity" [3] p. 464. Along these lines, we can examine a response in terms of its action efficacy - the degree to which the response is "the right action at the right time" [36] p. 254. With the sense and act components of agility, agile organizations are well positioned to respond to uncertainty [16]. But what exactly does it mean for organizations? To find out, we examine what constitutes agility in the disciplines of manufacturing, supply chain management, software development, strategy, and information systems.

Agility has origins in manufacturing and production where, as a competitive initiative, researchers advocate integrating production processes and other parts of the company into a totally integrated organization where information "flows seamlessly among manufacturing, engineering, marketing, purchasing, finance, inventory, sales and research departments" [30] p. 8. This supports concurrency in the processes of new product development, manufacturing and marketing. 
In manufacturing, agility is conceptualized as the ability to "take advantage of changes as opportunities" [38] p. 497. Thus, an agile manufacturer would have capabilities to respond to, for example, changes in market forces or new customer requirements. Key to each manufacturer's response is having the capability to turn the change into an opportunity. Manufacturers can attain this capability by integrating the business components of their organizations [17] or by simply having flexibility in areas such as manufacturing, people, and the organization [28]. Having attained this, the agile manufacturers are equipped to create opportunities out of changes.

In the supply chain management area, views of agility incorporate the capabilities of supply chain partners when detecting opportunities and responding to them. That is, a firm can improve its agile capabilities to detect and respond if it can "tap into the pool of external information held by supply-chain partners" while "designing products that are better aligned with the firm's sourcing and manufacturing capabilities" [4] p. 653. This coordination of agile efforts is enhanced by the use of IT [4], [29]. Specifically, the IT component of agility can be seen along the supply chain, where the impact of digital resources on digital agility can be viewed both inside a company... and in an ecosystem containing partners, suppliers, and other components of a business network [5] p. 480. This suggests that agility in the supply chain includes a flow of information and digital resources throughout the depth and breadth of a firm and its supply chain; this could be accomplished through traditional channels and even enhanced by the use of social media and cloud computing technologies [23], [42]. This is consistent with recent findings that suggest that operational agility may be enhanced by developing appropriate information processing capabilities [12].

In software development, agile methodologies (e.g. Rational Unified Processes, Scrum, Extreme Programming, Crystal Clear, etc.) can replace some or all of the traditional structured, waterfall development methodologies [7]. In doing so, agile teams break projects into several small, manageable chunks and frequently integrate them into a finished product that is visible to the end customer at all times [24], [32]. Along the lines of an agile supply chain paradigm, agile software teams develop software while detecting user requirement changes and development opportunities and then responding to them. The response component of software development agility comprises two dimensions: efficiency and effectiveness [22]. Each project may benefit from different levels of each dimension so project managers should evaluate the project goals of cost, schedule, and functionality and adjust the efficiency and effectiveness capabilities accordingly [22] p. 105. Having agile processes in place allows for a flexible development process that allows teams to respond to change in an efficient manner.

In the field of business strategy there is an increasing realization among researchers and practitioner alike that being able to change and adapt to the constantly evolving business environment is the only feasible long-term strategy [6]. This realization is largely a result of the turbulent, unpredictable, interconnected and fragile socio-economic environment in which businesses of today have to operate [6]. In order to achieve and sustain a competitive advantage in this type of an environment, organizations need to invest in developing dynamic capabilities that can be rapidly assembled and used in response to an emerging threat or opportunity [40]. In other words, a business needs to be highly responsive (or agile) in relation to its internal and external environment. Thus, in strategy, agility is conceptualized as a "comprehensive response to the business challenges of profiting from rapidly changing, continually fragmenting, global markets for high-quality, high-performance, customer-configured goods and services" [11] p. 4. With this, business leaders and strategists work to exploit changes and turn them into an advantage [44]. Importantly, an appropriate response supports a company goal and the changes to be sensed could be "precipitated by competitors' actions, consumer preference changes, regulatory or legal changes, economic shifts, technological advancements, etc." [33] p. 296.

In the field of IS, agility has received substantial attention as well. One of the early papers on the role of IT in enhancing organizational agility adopted a rather technical perspective on the issue, arguing that organizational agility is achieved via investments in improved IT assets and IT services [41]. Later studies adopted a broad, organizational perspective on the role played by IT in enhancing organizational agility. With that, IT applications assist the two important components of agility-sensing and responding- through internal and external integration [31]. Internal integration involves enhancing processes and cooperation involving internal stakeholders such as employees and organizational units. External integration requires the streamlining of processes involving external stakeholders such as customers, suppliers, and retailers. This is along the lines of the view that agility is the ability to rapidly respond to challenges and opportunities via internal flexibility and efficiency, leveraging various resources and capabilities, and coordinating the work of various internal and external stakeholders [37].

Once embraced, IT-enabled agility can have positive impacts on the performance of an organization. Firms build relational value and enhance their performance with IT capabilities that enable coordination of the flows of physical goods, information, and finances across locations in the supply chain. [35] p. 234. Further, the magnitude of the impact of agility on performance is greater in turbulent business environments compared to relatively stable business environments [39]. This is influenced by the alignment of IT with organizational goals because agility has a mediating role in the relationship between IT alignment and firm performance [39]. In addition to IT alignment, we can examine the alignment of the components of agility themselves- sensing and responding. The alignment between these two components is shown to impact a "firm's competitive activity" [36] p. 231.

The notion of agility has been extended in IS research to conceptualize two types of agility: market capitalizing agility and operational adjustment agility [27]. Market capitalizing agility consists of a firm's ability to quickly respond to and capitalize on changes by sensing needs. Operational adjustment agility is the ability for firms to respond by adjusting 
their "internal business processes to... cope with market or demand changes" [26] p. 933. Together, these form an important means of assessing agility in firms.

Noticeably in the current agility research stream and in most IS studies that examine the role of IT in enhancing agility, researchers view IT as an amorphous and all-encompassing entity rather than focus on the specific types of IT that can contribute to agility. What a manager needs is a focused understanding of how a particular type of IT can be used to enable organizational agility. Therefore, the main goal of this study is to address the following broad research question:

\section{$R Q:$ How can organizations use mobile technology for enhancing organizational agility?}

The next section discusses conceptual foundations used to address this research question.

\section{Conceptual Background}

To better understand how mobile technology may be used to enhance organizational agility, we first examine the three areas where information systems can contribute to organizational agility. After that, we use the u-commerce framework to propose specific ways of how mobility-driven information systems can enhance organizational agility. Taken together, these two theoretical frameworks form a conceptual foundation for our study.

\subsection{Agility and Information Systems}

This study adopts the perspective on the role of IS in improving organizational agility as outlined in [37], one of the seminal papers whose ideas have informed a plethora of subsequent IS agility studies. The authors define agility as the ability to detect opportunities for innovation and seize those competitive market opportunities by assembling requisite assets, knowledge, and relationships with speed and surprise (p. 245). In order for an organization to be agile, it must be collectively agile on three dimensions: operational, customer, and partnering (see Table 1).

Table 1: Agility framework (adopted from [37])

\begin{tabular}{|l|l|l|}
\hline Type of Agility & Description & Role of IT \\
\hline Operational & $\begin{array}{l}\text { Ability to accomplish speed, } \\
\text { accuracy, and cost economy in the } \\
\text { exploitation of opportunities }\end{array}$ & $\begin{array}{l}\text { Technologies for the modularization } \\
\text { and integration of business processes }\end{array}$ \\
\hline Customer & $\begin{array}{l}\text { Ability to co-opt customers in the } \\
\text { exploration and exploitation of } \\
\text { innovative opportunities: } \\
\text { - as sources of innovative ideas } \\
\text { - as co-creators of innovation } \\
\text { as users in testing ideas or } \\
\text { helping others learn about the } \\
\text { idea }\end{array}$ & $\begin{array}{l}\text { Technologies for building and } \\
\text { enhancing virtual customer } \\
\text { communities for product design, } \\
\text { feedback, and testing }\end{array}$ \\
\hline Partnering & $\begin{array}{l}\text { Ability to leverage the assets, } \\
\text { knowledge and competencies of } \\
\text { suppliers, distributors, contract } \\
\text { manufacturers, and logistics } \\
\text { providers in the exploration and } \\
\text { exploitation of innovative } \\
\text { opportunities }\end{array}$ & $\begin{array}{l}\text { Technologies facilitating inter-firm } \\
\text { collaboration, such as collaborative } \\
\text { platforms, collaborative portals, and } \\
\text { supply-chain systems }\end{array}$ \\
\hline
\end{tabular}

Operational agility refers to a firm's ability to rapidly modify existing processes or instantaneously create new processes in order to concur with changing marketplace conditions [37]. In an idealistic manner, a firm that displays the highest level of operational agility is one that is highly modular on the inside and thus flexible enough to arrange itself in a way that facilitates the rapid design (and re-design) of processes to produce a new good or service. Information technologies that support operational agility are able to mimic and interconnect a flexible modular structure. This could apply to traditional technologies, particularly those that support functional areas (e.g., procurement, manufacturing, accounting), which operate mostly independently. Providing high levels of interconnectivity combined with improved communications may not only enable a flexible constellation of these independent modules, but also promote efficient processes and thus operational agility.

Customer agility refers to a firm's ability to leverage a customer in a variety of forms: as a source of innovation, as a creator of innovation, and as a user of innovation [37]. A customer is treated as equal in the so-called value-network and is actively pursued as an initiator of innovation. Information technologies that support customer agility are 
primarily those that enhance customer communities. By providing an electronic channel to gather customers' feedback, a firm can leverage and initiate new processes around it, and thus increase customer agility.

As with customers, the relationship with partners plays an equally important role in the value-network constellation. Partnering agility refers to a firm's ability to rapidly redesign a firm's network of suppliers, distributors, contract manufacturers, and logistics providers in order to seize existing or to create new market opportunities [37]. Information technologies that support partnering agility are those that facilitate inter-firm collaboration. For example, by allowing partners to access the most comprehensive and most timely information, a firm can extend its operational agility to its partners, and with it, can increase the efficiency and effectiveness of its processes as well as the quality of information available for decision-making.

Together, the dimensions of customer, partnering, and operational agility form a framework for looking at agility from an information systems perspective. We will use this framework as one tenet of our analytical lens for exploring the question of how technology in general-and mobile technology in particular- can be an enabler of organizational agility.

\subsection{Mobile Technology as an Enabler of Organizational Agility}

Information systems that harness the capabilities of mobile technologies are increasingly commonplace in the workplace. Not only within the physical boundaries of an office but also when traveling, employees are able to wirelessly connect to a firm's network and stay informed and productive. Thus, business conducted using mobile technology is becoming an inseparable component of an employee's life.

Business conducted using mobile technologies (m-commerce) exhibits some characteristics that are truly distincparticularly when compared to e-commerce. First and foremost, m-commerce is not tied to a specific location (i.e., a wired outlet). Mobile devices can be used in a manner unconstrained by time and space, assuming that network coverage is sufficient. Individuals can access a wireless network at any point in time from anywhere, and in turn are reachable through the network at any point in time from anywhere- a characteristic that has been termed ubiquity in the IS literature [16] (see Table 2).

Mobile technology also supports what has been termed as uniqueness [16]. Uniqueness comprises two dimensions: identifiability and locatability (see Table 2). Identifiability refers to the very fact that one mobile device is exactly associated with one individual-even if that individual owns more than one device. With it, one device is always linked to one phone number, one name, and one billing address. In addition, mobile devices also store information about an individual, including his personal phone numbers, calendars, personal notes, favorites, and email files. A mobile device can therefore be viewed as the virtual embodiment of an individual, representing his digital persona. The other dimension, locatability, aids identifiability by providing a geographic component. In the form of location-based services, for example, applications are available that take into account the geographic whereabouts of a mobile device-and with it, its carrier [14]. Services include car navigation systems, location-sensitive billing (e.g., paying while passing toll stations on highways), and location-specific store advertisements that are sent to a consumer's mobile device when the individual is in close proximity. Taken together, the ability of mobile technologies to provide the identity of a mobile user and the ability to determine his geographic position leads to uniqueness- knowing who the individual is and where he is.

Table 2: U-Framework (adapted from [10])

\begin{tabular}{|l|l|l|l|}
\hline Characteristic & Description & U-Construct & Description \\
\hline Reachability & $\begin{array}{l}\text { An individual can be } \\
\text { reached by others at any } \\
\text { time and at any location }\end{array}$ & Ubiquity & $\begin{array}{l}\text { Ubiquity describes the } \\
\text { quest to have access to } \\
\text { information } \\
\text { unconstrained by time } \\
\text { and space. }\end{array}$ \\
\hline Accessibility & $\begin{array}{l}\text { An individual can access } \\
\text { the network at any time and } \\
\text { at any location }\end{array}$ & $\begin{array}{l}\text { An individual can be located } \\
\text { geographically }\end{array}$ & $\begin{array}{l}\text { Uniqueness describes } \\
\text { the quest to know } \\
\text { precisely the } \\
\text { characteristics and } \\
\text { location of a person or } \\
\text { entity. }\end{array}$ \\
\hline
\end{tabular}

\subsection{The Mobile Agility Framework}

In this paper, we argue that mobile technology can be an enabler of organizational agility due to its unique characteristics of ubiquity and uniqueness. With regards to ubiquity, we argue that its benefit yields technological flexibility and efficiency on the dimensions of time and space. Time and space are major constraints of the reality around us [25]. For example, they limit a company's ability to respond to rapid changes in the marketplace and to 
take advantage of emerging opportunities. But when one is not limited by spatial and temporal dimensions, response is not a problem. Consider, for example, a large and chaotic battlefield (it resembles some of today's turbulent and rapidly changing marketplaces). On the battlefield, given that an army possesses adequate resources, a sudden attack of an enemy can always be neutralized, and a sudden opportunity for advancement can always be taken advantage of if the army could always concentrate its resources at the right place, at the right time.

Sambamurthy et al. [37] propose a similar strategy for business. According to them, a company can effectively respond to sudden challenges and exploit emerging opportunities by assembling requisite assets, knowledge, and relationships with speed and surprise [p. 245]. Using mobile technology to alleviate temporal and spatial constraints due to the ubiquity of technology, a firm can better connect with employees, customers, suppliers, and business partners [9]. This improved flexibility on the dimensions of time and space can potentially enhance all three dimensions of organizational agility (see Table 3) and-ultimately- create competitive advantage.

Table 3: Mobile agility framework (based on [16], [37])

\begin{tabular}{|l|l|l|}
\cline { 2 - 3 } \multicolumn{1}{c|}{} & Ubiquity & Uniqueness \\
\hline Operational agility & $\begin{array}{l}\text { Wirelessly accessible module and } \\
\text { integration capabilities }\end{array}$ & $\begin{array}{l}\text { Personalized and location-based } \\
\text { module and integration } \\
\text { capabilities }\end{array}$ \\
\hline Customer agility & $\begin{array}{l}\text { Wirelessly accessible customer } \\
\text { communities }\end{array}$ & $\begin{array}{l}\text { Personalized and location-based } \\
\text { customer communities }\end{array}$ \\
\hline Partnering agility & $\begin{array}{l}\text { Wirelessly accessible inter-firm } \\
\text { collaboration capabilities }\end{array}$ & $\begin{array}{l}\text { Personalized and location-based } \\
\text { inter-firm collaboration } \\
\text { capabilities }\end{array}$ \\
\hline
\end{tabular}

In the same vein, the uniqueness aspect of technology can potentially enhance all three dimensions of organizational agility and, as a result, create competitive advantage (see Table 3). Uniqueness increases the identifiability and locatability of assets, knowledge and relationships. More specifically, it enhances knowledge management processes, i.e., the creation, storage, retrieval, transfer, and application of knowledge within the organization [1]. As organizational knowledge can be either individual (i.e., created by and inherent in the individual) or social (created by and inherent in [the] collective actions of a group) [p. 113], being able to identify and locate carriers of individual knowledge with the help of mobile technology may enhance the efficiency with which social knowledge is created, transferred, and applied. Also, in the realm of relationships, researchers suggest that beneficial relationships between the IS function and business are promoted by coordinating and communicating extensively together [34], $p$. 756. Thus, being able to identify as well as locate individuals-both within and outside of organizational boundariesmay enhance coordination and communication inside the organization as well as the coordination and communication with customers and partners. This improved capability to assemble assets, knowledge, and relationships can be applied to all three levels of organizational agility.

In the following, we will apply the mobile agility framework depicted in Table 3 as our guiding lens in the quest for studying how mobile technology is used as an enabler of three dimensions of organizational agility: operational, customer, and partnering. With it, we will not only be able to identify how it is currently used, but also identify the blind spots in the theoretical understandings of the role of mobile technology in supporting organizational agility. This will enable us to raise questions that IS researchers as well as practitioners have to consider when pursuing the deployment of mobile technology with the intent to achieve organizational agility.

\section{Methodology}

We adopt a case study-based approach to address the broad research question of how organizations use mobile technology for enhancing organizational agility. In the following sections, we lay out the rationale, data sources, and research protocols for the study.

\subsection{Multiple Case Study Approach}

This study adopts a multiple case study approach to answer the research question of how organizations can use mobile technology to enhance organizational agility. The case study method has a strong tradition in the field of IS [20]. According to [43], the case study method is the preferred research approach for answering how and why questions in the context of contemporary events where no behavioral control of events is required. These characteristics of the case study are well-aligned with the main research question of this study: how mobile technology can be used to improve organizational agility. In this study, we attempt to uncover the specific 
mechanisms that can be used by organizations to enhance agility with the help of mobile technology (the how component). Moreover, we attempt to ground explanations of how agility is achieved with mobile technology in a preliminary theoretical framework discussed in the Conceptual Background section (the why component). While the case study method has some inherent weaknesses related to ambiguous rigor standards, lack of control over variables, and thus, limited generalizability, it can be used for preliminary theory building [20], [21], [43]. In order to compensate for these inherent weaknesses of the case study method, this study adopts a multiple-case study approach. According to [43], a multiple case study approach is often regarded as richer and more robust than a single-case study approach. Moreover, the evidence collected using the multiple case study approach is often viewed as more persuasive since a multiple case study design allows for a higher degree of generalizability of findings. A similar research approach relying on multiple archival case studies was used by [2] in an attempt to propose a preliminary theoretical framework that can explain how e-business creates value for organizations and guide companies in using the Internet for improving organizational performance.

\subsection{Source of Case Data}

In this study, we analyze 198 case studies published by Hewlett-Packard on its website (Site 1). These case studies describe how mobile technology was implemented across varying organizational contexts and industries. Each case provided by HP contained the following pieces of information: a description of the objective of the mobile implementation, a short description of the implementation procedures as well as the anticipated and unanticipated results and benefits. This archival data source represents a broad and comprehensive set of documented mobile technology implementations.

Due to the relative novelty of the phenomenon and the lack of prior theorization, having a sample available that explores differing organizational contexts as well as differing industries is of utmost importance in order to gain an initial understanding of how mobile technology enhances organizational agility. We acknowledge the fact that this is largely a convenience sample and we rely on data from one company only. However, this is outweighed by the homogeneous, rich and diverse descriptions of mobile implementations found in these cases. As the objective of the paper is not to confirm but rather propose a theoretical framework that can be used as a guiding instrument in the quest of identifying agility benefits that are derived from mobile technology, we argue that the sample is well suited for its purpose.

\subsection{Research Protocol}

Our data analysis comprised several steps. The first step involved initial screening of available material by the coders. After the screening, 109 case studies were dropped from further analysis. A case was excluded either (a) because it discussed benefits of mobile technology in general terms, without referring to specific organization or implementation projects, or (b) because it discussed an IT solution that was only distantly related to mobile technology. The remaining sample of 89 case studies was used for further analysis. Each of the 89 cases used in this study had sufficient information on how mobile technologies were used by organization to create organizational value.

In a second step, each case study was read with the purpose of identifying specific benefits achieved along the agility/mobility areas identified in the framework introduced in Table 3. Cases were categorized into a subcategory of agility (i.e., customer, partnering, or operational) and a subcategory of mobility (i.e., ubiquity and uniqueness) by asking a set of six specific questions:

Does ubiquity lead to operational agility? If yes, how?

Does uniqueness lead to operational agility? If yes, how?

Does ubiquity lead to customer agility? If yes, how?

Does uniqueness lead to customer agility? If yes, how?

Does ubiquity lead to partnering agility? If yes, how?

Does uniqueness lead to partnering agility? If yes, how?

Three coders were involved in analyzing and categorizing each case study. A Microsoft (MS) Word-based template for tabulating and recording case classifications was used by each of the raters. The templates were later used to compare the results among the three coders and resolve any inconsistencies. Overall, the inter-rater reliability was high. Discrepancies in classifications were resolved via a discussion resulting in consensus among the coders.

The third (and final) step comprised selecting illustrative examples for each category in the proposed framework. Examples were chosen to provide a broad range of illustrations across different industries and functional areas in a 
company. Examples were selected by the first author of this paper. The results of this analysis can be found in Tables 4 through 9.

\section{Findings}

A total of 89 cases were analyzed for the purpose of determining how characteristics of mobile technology may contribute to the creation of agility-enhancing benefits which, in turn, contribute to operational, customer, and partnering agility. The frequency distribution of the cases are summarized in Table 4, with each of the six cells representing how often a particular agility dimension was coupled with a particular mobile dimension.

Table 4: Frequency distribution of the mobile agility framework

\begin{tabular}{|l|l|l|l|}
\cline { 2 - 4 } \multicolumn{1}{c|}{} & Ubiquity & Uniqueness & Total \\
\hline $\begin{array}{l}\text { Operational } \\
\text { Agility }\end{array}$ & 50 & 9 & 59 \\
\hline $\begin{array}{l}\text { Customer } \\
\text { Agility }\end{array}$ & 22 & 4 & 26 \\
\hline $\begin{array}{l}\text { Partnering } \\
\text { Agility }\end{array}$ & 4 & 0 & 4 \\
\hline Total & 76 & 13 & 89 \\
\hline
\end{tabular}

For example, our analysis uncovered 59 cases that were found to contain information on how mobile technology enhances operational agility through ubiquity (50 cases) and through uniqueness ( 9 cases) by creating agilityenhancing benefits such as improved availability of information irrespective of time and space, improved quality of information based on the transcendence of time and space, and improved intra-organizational communication unrestricted by time and space. Similarly, a total of 26 cases were found to contain information on how mobile technology enhances customer agility through ubiquity (22 cases) and uniqueness ( 4 cases) by creating agilityenhancing benefits such as serving customers at their site, in a timely manner, and creating new value propositions using mobile technology. Finally, only 4 cases were found to contain information on how mobile technology enhances partnering agility through ubiquity by creating the agility-enhancing benefit of improved efficiency in existing partnerships. Note that none of the 89 cases showed a simultaneous occurrence of partnering agility and uniqueness.

While these findings provide insights into the distribution of mobility and agility benefits, they do not demonstrate how the two interact. To address this issue, we discuss the findings with respect to their agility-enhancing benefits in the following six subsections, each of which represents an intersection between an agility dimension and a mobile dimension. For each cell, we have chosen exemplary cases that serve as the basis for our discussion. We start with the most frequently used constellation of mobility and agility and gradually move towards the least applied constellation. By drawing on this analysis, we attempt to pinpoint potential issues and questions that both practitioners and researchers may want to address in order to take organizational agility to the next level and increase the understanding of organizational agility enabled by mobile technology.

\subsection{Ubiquity Enhances Operational Agility by Improving the Availability and Quality of Information as well as Intra-Organizational Communication}

The category of how ubiquity enhances operational agility contains many exemplary cases (see Table 5). In fact, this category was the most widely utilized one in our analysis with 50 instances. For example, Hewlett-Packard (HP) customer engineers use laptops with wireless capabilities to access information anywhere and anytime. Better access to information allows them to solve customers' problems faster. This not only results in time savings for the engineers, but also in lower support costs for HP, and an increase in customer satisfaction. In another case, the Ontario, California Police Department uses handheld devices with wireless connectivity to check fingerprints on the spot. If a suspect does not provide his identification or resists revealing his real name, a police officer can capture the suspect's fingerprints and connect wirelessly to a centralized database in order to find a match. Ability to access important information in the examples cited above is largely enhanced by the ability of employees to access information anywhere, anytime.

While these findings indicate a clear benefit from ubiquity, some cases highlight instances of varying levels of ubiquity. For example, consider the two utility company cases: Bernische Kraftwerke (BKW) Energie Aktiengesellschaft (AG) and Basel-Stadt Baudepartement. BKW equipped its meter-readers with wireless-enabled 
mobile computers, thus enabling them to record readings on the spot and to transmit this information to headquarters immediately. In contrast, Basel-Stadt who also issued mobile computers to its meter-readers does not transmit its information immediately, but waits until the end of each workday to collect the readings via hard-wired synchronization. While the BKW case makes the most exhaustive use of ubiquity by feeding its information into the system in the timeliest manner possible, Basel-Stadt is satisfied with a lesser degree of timely information. For them, having the most recent information available on a continuous basis may not be a feasible goal since it may require significant economic expenditures that may not be justified. In other areas, such as mission-critical applications, however, the expenditure might be justified. Police officers, firefighters, doctors, and soldiers are often involved in situations where efficiency with respect to time and space is not a matter of cost or increased productivity, but a question of life or death. This suggests that mobile technology can be a necessary attribute of spatial and temporal agility in applications where the cost of failure is too high. Thus, a potential question that needs to be addressed is the following:

Q1: Do different organizations require different levels of ubiquity? If so, what is the optimal level of ubiquity for various applications and contexts?

Within this category, we found three forms of benefits to be most eminent: the improved availability of information irrespective of time and space, the improved quality of information based on the transcendence of time and space, and the improved intra-organizational communication unrestricted by time and space. Overall, this category is exemplary of mobile technology delivering efficiency and effectiveness gains-or in other words, and as proposed by [37], delivering speed, accuracy, and cost economy in the exploitation of opportunities [p. 238].

An analogous deployment of technology was witnessed with the implementation progression of enterprise-wide systems in the 1990's. The initial focus of enterprise systems was primarily geared towards an increase in intraorganizational operational performance. Only in a second step did extra-organizational entities, such as customers and suppliers, become part of the process considerations in form of supply chain and customer management systems [26]. In the context of mobile technology, the same path seems to apply. In a first step, firms utilize mobile technology solely at an operational level; only gradually do they deploy it to their external entities. In fact, applying mobile technology for intra-organizational usage first seems to create enough sizable benefits (e.g., in form of cost reductions) to justify the deployment of the technology. Utilizing the most obvious mobile technology characteristic first, i.e., ubiquity, seems to be more common than making use of the uniqueness component, as described in the following.

Table 5: Exemplary cases of operational agility and ubiquity

\begin{tabular}{|l|l|}
\hline Company & Description \\
\hline Hewlett Packard & $\begin{array}{l}\text { With the help of laptops with wireless capabilities, Hewlett Packard customer } \\
\text { support engineers can access information related to customer requests from } \\
\text { anywhere/anytime. Better access to information allows the engineers solve } \\
\text { customers' problems faster, which translates into time savings for engineers, } \\
\text { lower support costs for HP, and increased customer satisfaction. }\end{array}$ \\
\hline $\begin{array}{l}\text { Skidmore, } \\
\text { Owings \& Merill, } \\
\text { LLP }\end{array}$ & $\begin{array}{l}\text { Architects at Skidmore, Owings \& Merill, LLP use tablet PCs to work } \\
\text { collaboratively on drawings. Tablet PCs make it easier for architects to } \\
\text { communicate their design ideas and get feedback from their colleagues. } \\
\text { Paper-based exchange of design ideas has proven itself to be less time } \\
\text { efficient and more inhibitive to creativity. }\end{array}$ \\
\hline $\begin{array}{l}\text { Ontario, } \\
\text { California Police } \\
\text { Department }\end{array}$ & $\begin{array}{l}\text { Public servants with the Ontario, California Police Department use mobile, } \\
\text { handheld devices to identify subjects by reading their fingerprints and } \\
\text { comparing them with those in law enforcement databases. }\end{array}$ \\
\hline BKW Energie & $\begin{array}{l}\text { Meter readers for Swiss electricity provider BKW Energie use wireless- } \\
\text { enabled mobile computers to record and transmit electric usage data. The } \\
\text { tools improve accuracy by validating each reading as it is entered; also, the } \\
\text { tools eliminate the need to travel to office to submit readings. }\end{array}$ \\
\hline $\begin{array}{l}\text { Basel-Stadt Baudepartement, the building department in the city of Basel, } \\
\text { Switzerland, uses mobile computers to collect information about the } \\
\text { Baudepartement } \\
\text { consumption of water, natural gas, and electricity in city buildings. The } \\
\text { system allows employees to enter the data at several usage sites and then } \\
\text { download it into a city computer once they return to the main office. }\end{array}$ \\
\hline
\end{tabular}

\subsection{Uniqueness Enhances Operational Agility by Improving the Quality of Information}

Only nine cases utilized uniqueness in order to achieve operational agility (see Table 6). For example, the geotracking solution developed by HP and Paradigm Advanced Technologies, Inc. uses a global positioning system (GPS) to continuously capture, integrate, and transmit status and location information of personnel and equipment. The system was successfully used by the City of New York in order to manage its fleet of debris-removing trucks 
during the cleanup resulting from the destruction of the World Trade Center. Similarly, search and rescue personnel in Finland use a mobile computer system developed by Lentopelastus to identify the location of their search target. The system utilizes digital copies of ground-based police and fire service maps to allow the search personnel to share more useful location information with other emergency services units. Ubiquitous networks and the ability to locate assets are the key factors that improve the timeliness of information, and with it, the overall quality of information.

But what about locating entities other than humans? A palette of sodas (or any other consumer product) often needs to be tracked for logistical purposes. For example, Wal-Mart, a giant US retailer, was experimenting with Radio Frequency Identification (RFID)- a wireless identification technology that tracks its products along the supply chain [19]. In the same vein, the German based METRO Group is conducting pilot projects with suppliers, warehouses, and retail stores involving using RFID to track palettes from supplier to customer [13]. However, and as witnessed in the cases, the localization of non-human objects (or assets) has been mostly neglected. IS researchers as well as practitioners therefore need to ask the following question:

Q2: What are the factors that contribute to the integration of locatability between human and non-human entities? How can both be put in relative context to each other in order to benefit organizations?

Table 6: Exemplary cases of operational agility and uniqueness

\begin{tabular}{|l|l|}
\hline Company & Description \\
\hline $\begin{array}{l}\text { Paradigm } \\
\text { Advanced } \\
\text { Technologies, } \\
\text { Inc. }\end{array}$ & $\begin{array}{l}\text { The geo-tracking solution developed by HP and Paradigm Advanced } \\
\text { Technologies, Inc. uses a global positioning system (GPS) to continuously } \\
\text { capture, integrate, and transmit status and location information for personnel } \\
\text { and equipment. The system was used successfully by the City of New York in } \\
\text { order to manage its fleet of debris-removing trucks during the cleanup } \\
\text { resulting from the destruction of the World Trade Center. }\end{array}$ \\
\hline & $\begin{array}{l}\text { Aircraft-based search and rescue personnel in Finland use Lentopelastus } \\
\text { developed mobile computer systems to identify the location of their search } \\
\text { target. The system utilizes digital copies of ground-based police and fire } \\
\text { service maps to allow the search personnel to share more useful location } \\
\text { information with other emergency services units. }\end{array}$ \\
\hline
\end{tabular}

\subsection{Ubiquity Enhances Customer Agility by Enabling On-Site, On-Time Customer Service}

Our analysis showed that cases using ubiquity in order to enhance customer agility ranked second with regards to the frequency of deployment (i.e., 22 instances). Some of the case studies in this category illustrate how businesses use mobile technology to take advantage of ubiquity by serving customers on-site and on-time (see Table 7). For example, because inspectors at the city of Bellevue, Washington, have ubiquitous access to their network; they are able to issue permits and carry out inspections of construction projects on-site. This eliminates the need to travel back and forth between a construction site and the city office and allows inspectors to provide feedback to their clients on an ad hoc basis. In another case, housekeepers at the Pacific Terrace hotel use PDAs with wireless connectivity to accommodate customers' requests about their rooms on the fly, thus, enabling the ability to react to a customer demand instantaneously.

Although cases in this category were found to rely on ubiquity to create agility-enhancing benefits, the level of ubiquity-as described in these cases- varied. For example, pilots at Air Routing International achieved a high level of ubiquity, but to do so, they had to occasionally swap their network cards of their mobile computers in order to ensure communication compatibility across continents. Along these lines, some users achieved ubiquity by working in Wi-Fi hotspots. A realtor in the John L. Scott Real Estate case, for example, met his client in a local coffee shop that offered wireless access. Both cases represent what we refer to as partial ubiquity. Even though we classified both cases as ubiquitous, they did not use ubiquity in its complete form because individuals were tasked with the burden of achieving it. In a truly ubiquitous environment, an individual would have network access and be reachable any time and at any place. The gap between our findings and the ultimate form of ubiquity leads to the following question:

\section{Q3: Is it of organizational importance to achieve ultimate ubiquity? If so, what steps are necessary?}

Addressing this question requires the resolution of several other issues. For example, what technical problems need to be resolved, and what technical standards are required that need to be agreed upon? What are the consequences for the design and development of new products? And who are the beneficiaries of true ubiquity?

Our pool of data suggests that mobile technology is most likely to be adopted and used with significant improvements in efficiency and effectiveness by the nomadic professionals-that is, professionals whose daily work involves a large amount of travel. Lawyers, sales people, police officers, and property insurance agents are typical 
examples. It is clear that the need to have access to personalized information irrespective of time and space makes nomadic professionals highly dependent on technological ubiquity. At the same time, professionals that traditionally were assumed to be stationary (such as customer support engineers) may also derive benefits from leaving their offices and moving closer to their customers. We therefore expect that not only professionals with high degrees of nomadicity will utilize mobile technology as part of their businesses, but progressively also those with lower demands for mobility. Overall, such a transformation not only leads to more efficient customer service, but also to greater customer satisfaction.

Table 7: Exemplary cases of customer agility and ubiquity

\begin{tabular}{|l|l|}
\hline Company & Description \\
\hline $\begin{array}{l}\text { Air Routing } \\
\text { International }\end{array}$ & $\begin{array}{l}\text { Using a mobile computer, corporate jet pilots access real-time flight plan and } \\
\text { weather data from Air Routing International. The service is in-flight, but the } \\
\text { pilots must use different communication cards while traveling over some } \\
\text { continents. }\end{array}$ \\
\hline $\begin{array}{l}\text { Capital Care } \\
\text { Medical } \\
\text { Group }\end{array}$ & $\begin{array}{l}\text { With the help of mobile technology, physicians at Capital Care Medical Group } \\
\text { are able to access treatment information faster and from any place in the } \\
\text { hospital. Resulting time savings allow physicians to spend more time with } \\
\text { their patients. }\end{array}$ \\
\hline $\begin{array}{l}\text { City of } \\
\text { Bellevue, } \\
\text { Washington }\end{array}$ & $\begin{array}{l}\text { Inspectors at the City of Bellevue, Washington use personal digital assistants } \\
\text { (PDAs) and notebooks with wireless Internet to inspect and issue permits for } \\
\text { construction projects. Previously, in order to comply with regulations, a } \\
\text { builder had to make several trips to a city office. }\end{array}$ \\
\hline $\begin{array}{l}\text { John L. Scott } \\
\text { Real Estate }\end{array}$ & $\begin{array}{l}\text { A realtor in the John L. Scott Real Estate use tablet personal computers } \\
\text { (PCs) to bring his office closer to his clients. Meetings with clients are held in } \\
\text { coffee shops near customer locations. Using a wireless network provided at a } \\
\text { coffee shop, realtors can pull all the relevant information needed to address } \\
\text { customers' questions. }\end{array}$ \\
\hline $\begin{array}{l}\text { Buttermilks } \\
\text { Country } \\
\text { Restaurant }\end{array}$ & $\begin{array}{l}\text { The staff at Buttermilks Country Restaurant process orders electronically } \\
\text { using mobile computers. The technology wirelessly sends orders to the } \\
\text { kitchen and results in faster, more accurate service. }\end{array}$ \\
\hline $\begin{array}{l}\text { Pacific } \\
\text { Terrace }\end{array}$ & $\begin{array}{l}\text { Housekeepers at the Pacific Terrace hotel use PDAs with wireless } \\
\text { connectivity to accommodate customers' requests about their rooms on the } \\
\text { fly, thus, enabling to react to a customer demand instantaneously. }\end{array}$ \\
\hline
\end{tabular}

\subsection{Uniqueness Helps Creating New Value Propositions for Customers}

Only four cases illustrate how uniqueness may improve existing customer-oriented processes and create new business opportunities. Here, customers serve as the source for innovation as well as the co-creators in the innovation process (see Table 8). For example, the Royal Sonesta Hotel Boston uses personal digital assistants (PDAs) with wireless capabilities to enhance a visitor's experience at its art gallery. Guests wishing to visit the gallery are provided with a PDA. When a guest stops near a particular art piece, information such as the artist's name, title of his work, and sometimes even anecdotes, are sent to the visitor's PDA. Another application that uses a GPSequipped mobile computer from HumanWare Group provides support for visually impaired customers on the street. As they travel, the system announces street names, addresses, and upcoming businesses. Yet, another example is Sunrise, a Swiss mobile telecommunications company. Sunrise allows their mobile customers to pay landline phone rates instead of significantly higher mobile within their personal zones. A customer's personal zone is determined by calculating where the subscriber places and receives the highest number of calls on his cell phone. This innovation helped Sunrise to encourage customers to use their cell phones as a primary means of communications, which led to a significant growth in revenues per customer and an overall expansion of their client base. As a tourist application, Timespots rents electronic guide books (wireless-enabled mobile PCs equipped with GPS) to visiting tourists. Using these guide books, tourists can access up-to-date maps and guides as well as receive location-based information about nearby restaurants, hotels, and tourist attractions. This ability of creating new value propositions to customers is primarily driven by the ability to uniquely identify a customer combined with the ability to determine geographic whereabouts.

While some of the cases in this category focus on both components of uniqueness (for example, Sunrise who provides personalized services based on a consumer's location), the majority of cases center around the localization dimension by leveraging an individual's geographical position. Identifiability, on the other hand, and its associated components, such as preferences and personalization opportunities, is far from being exploited-with Sunrise being the only example. As an individual has specific needs in a specific context, matching up environment and personal preferences using mobile technology seems desirable. For example, in the Royal Sonesta Hotel case, a PDA would not only determine where a user is, but also remember that the individual likes van Gogh paintings. Instead of corralling the individual through the baroque paintings which he may dislike, the mobile device would steer him right in the direction of van Gogh. Other applications, particular in the area of mission-critical applications, would highly 
benefit from uniqueness as well. Having context-specific information available that is geared towards an individual's specific needs is highly desirable in order to deliver the best quality of service on time and on the spot. For example, an advanced version of the E911 emergency service would not only determine a person's location and send appropriate personnel such as an ambulance, but would also know about an individual's allergic propensity towards particular medications. This information could potentially be stored on the phone, or alternatively, could be retrieved through the phone by remotely accessing a medical database. In our analysis, however, we did not evidence any case that would make use of such an application. This lack of uniqueness in the findings leads to the following question:

Q4: What are factors that contribute to exploiting the benefits of uniqueness? What steps are necessary in order to take customer uniqueness to a new level?

Table 8: Exemplary cases of customer agility and uniqueness

\begin{tabular}{|c|c|}
\hline Company & Description \\
\hline $\begin{array}{l}\text { Royal } \\
\text { Sonesta } \\
\text { Hotel Boston }\end{array}$ & $\begin{array}{l}\text { Royal Sonesta Hotel Boston enhances customer experience with the art } \\
\text { gallery exhibited at the hotel. Guests wishing to visit the gallery are given a } \\
\text { PDA with wireless capabilities. When a guest stops near a particular art } \\
\text { piece, visual and textual information is sent to the guest's PDA. This } \\
\text { information may include the artists' name, title of the work, and anecdotal } \\
\text { information about the work. This solution presents the hotel's art in an } \\
\text { inventive, engaging manner and allows the hotel to maximize the value of its } \\
\text { investment in the art collection. }\end{array}$ \\
\hline $\begin{array}{l}\text { HumanWare } \\
\text { Group }\end{array}$ & $\begin{array}{l}\text { Visually impaired pedestrians can function better using a Mobile computers } \\
\text { configured with a travel tool developed by the HumanWare Group. With it, } \\
\text { each GPS-equipped Mobile computer announces street names, addresses, } \\
\text { and upcoming businesses. }\end{array}$ \\
\hline Sunrise & $\begin{array}{l}\text { Sunrise, a Swiss mobile telecommunications company, deployed myzone-a } \\
\text { new service that enables mobile customers to pay land-line phone rates } \\
\text { instead of higher mobile rates within their personal zones. A customer's } \\
\text { personal zone is determined by calculating where the customer makes and } \\
\text { receives the highest number of calls. This innovation helped Sunrise to } \\
\text { encourage customers to use their cell phones as a primary means of } \\
\text { communication, which lead to a significant growth in revenues per customer } \\
\text { and expansion of the client base. }\end{array}$ \\
\hline Timespots & $\begin{array}{l}\text { Timespots rents electronic guide books to tourists in Amsterdam. The } \\
\text { guidebooks are wireless-enabled mobile PCs equipped with GPS. Tourists } \\
\text { can access up to date maps and guides as well as receive location-based } \\
\text { information about nearby restaurants, hotels, and tourist attractions. }\end{array}$ \\
\hline
\end{tabular}

\subsection{Ubiquity Enables Greater Efficiency of Partnering Arrangements}

Our analysis showed that cases using ubiquity in order to enable partnering agility were under-represented. For this category, we only found four instances (see Table 9). For example, the sales force at Camelot Group uses mobile technology to get more accurate and timely information from their partner retailers; they are also able to add new partner retailers to their system on an ad-hoc basis. While we categorized this as enabling partnering, it could be argued that a salesperson creates the partnership while the mobile technology simply enables documentation of the arrangement. Ideally, the mobile technology in a ubiquitous environment should play a more critical role in the partnership. Similarly, the Hotel Valencia uses the hotel-wide wireless connectivity to enhance collaboration between its value chain elements. Value chain elements are not usually classified as partners. However, we retained this case to illustrate the possibilities of partnering arrangements using mobile technology. For example, a hotel may use subcontractors for cleaning and catering services instead of providing these services in-house. In this case, these units become partners rather than value chain units.

With this, we envision ubiquity to be an enabler of value networks that facilitate the ad-hoc arrangement of modular entities in order to act and react faster to market and conditions. Mobile technology allows partners not only to wirelessly link in a flexible way and rapidly adjust processes to produce a novel good or service, but also would allow them to unlink and attach to others at will. In this way, mobile technology has the potential, even though not witnessed in our sample set, to take partnering a step further. We attribute the lack of cases in this category to the nature of partnering, which requires close cooperation between organizations and other numerous complexities in order to ensure mutual benefit. In the cases that we found to be related to partnering, the extent of cooperation was limited due to an isolated use of mobile information systems. As we expect more and more companies to equip information systems with mobile capabilities, the technical foundation will be laid for firms to cooperate on an ad-hoc and instantaneous basis. With the help of ubiquitous connectivity that supports integration efforts among partners, 
value networks that provide the most efficient process to generate a service or product will become reality. Until then, however, IS researchers as well as practitioners have to ask the following question:

Q5: What are factors that contribute to utilizing ubiquity in the creation of new partnerships? What steps are necessary to facilitate this?

Table 9: Exemplary cases of partnering agility and ubiquity

\begin{tabular}{|l|l|}
\hline Company & Description \\
\hline $\begin{array}{l}\text { Camelot } \\
\text { Group, plc. }\end{array}$ & $\begin{array}{l}\text { The sales force at lottery operator Camelot Group, plc. conduct business } \\
\text { using wireless-enabled tablet PCs. The tablets allow for real-time access to } \\
\text { sales data and also provide a means to promptly add new partner retailers to } \\
\text { the system. }\end{array}$ \\
\hline $\begin{array}{l}\text { Guests at Hotel Valencia enjoy the benefits hotel-wide wireless connectivity. } \\
\text { Check-in is conducted at curbside where the staff accepts credit card } \\
\text { information and then issues an electronic key, bypassing the front desk. Hotel } \\
\text { Valenciars using the WLAN do so via a portal that provides information about } \\
\text { hotel services as well as those of nearby partner businesses. And the hotel } \\
\text { plans on using wireless beacon technology to advertise their hotel services at } \\
\text { their partners' locations. }\end{array}$ \\
\hline $\begin{array}{l}\text { Boston } \\
\text { Athletic }\end{array}$ & $\begin{array}{l}\text { Officials at the Boston Athletic Association feed real-time results of the } \\
\text { Boston Marathon to members of the media in order to encourage press } \\
\text { coverage of the event. The system relies on special sensors and also field } \\
\text { personnel who monitor strategic locations to gather race data and then } \\
\text { instantaneously submit it using wireless-enabled mobile computers. }\end{array}$ \\
\hline $\begin{array}{l}\text { Sommet } \\
\text { D'evian }\end{array}$ & $\begin{array}{l}\text { Leaders participating in the 2003 G8 Summit in Evian, France utilized a tablet } \\
\text { system enabled real-time collaboration and information sharing between the } \\
\text { leaders and their support staffs, and this, in turn, facilitated partnering and } \\
\text { agreements among the leaders. }\end{array}$ \\
\hline
\end{tabular}

\subsection{Uniqueness Enables the Creation of New Partnerships}

While we still believe that uniqueness has the potential to create new partnerships, our exploratory study did not uncover any instances of this constellation. As a result, we cannot display any exemplary cases in this category. However, since the exploration of new partnership opportunities using the uniqueness dimension is important, we felt that it is justified to illustrate the constellation with a hypothetical case. Consider the case of a researcher who attends a large academic conference and who is interested in a specific topic. Having the opportunity of face-to-face interactions with other researchers who work in the same research domain would be beneficial. However, in a complex social setting, such as a conference, chances are small that the researcher would serendipitously run into the right partner, and chances are even less that the correct topic would come up in conversion. But if we assume that both attendees had a mobile device that wirelessly stored and announced their research preferences and objectives to one another, the likelihood of matching up similar interests and generating mutual awareness is alleviated. Critics might say that the above scenario could be accomplished via other means, such as membership in special interest groups or in virtual communities. However, there are still missing facets that provide additional value. Given that the researcher was attending the conference anyway, the mobile device made the best use of his time by seeking out those with similar interests. Using localization capabilities, the system can alert a researcher when a potential collaboration partner is nearby. This means, physical interaction is not only limited to the duration of the conference, but would also apply when riding the train to and from the airport or even while on the airplane. Considering our simple example, it is imaginable that uniqueness increases the potential for forming partnerships while going about our days. And in this case, the uniqueness-rather than the individual himself- is the enabler of partnerships. Nevertheless, lack of examples on leveraging uniqueness for establishing new partnerships with the help of mobile technology as well as the overall scarcity of cases demonstrating using mobile technology to form and support partnerships raise the following questions:

Q6: Why are businesses lagging behind in using mobility to develop new partnerships? Is there simply not a solid business case that supports its use or is the technology just waiting for early adopters?

\section{Discussion}

Several findings can be inferred from our study. First, uniqueness is under-utilized for achieving organizational agility. Organizations can use the uniqueness property of mobile technology to localize human and non-human subjects. Combining information about the location of an asset with other relevant sources of information can improve the quality of decisions, speed of operations, and overall effectiveness of an operational unit in response to emerging 
threats or opportunities. Uniqueness can also be leveraged to localize and identify customers and use this information to create additional value propositions for them. Identification can be utilized to personalize experiences for customers accessing a company's products and services via mobile devices, while localization can be used to further contextualize these products and services. Together, personalized products and services might lead to differentiation and competitiveness. Further, uniqueness can be used by organizations to retrieve information about potential partners, making the process of establishing new partnerships easier. Analogously, companies should ramp up their understanding of uniqueness for achieving organizational agility.

Second, ubiquity still has a couple of technical hurdles to overcome, but its ability to contribute to organizational agility seems established. Organizations can use ubiquity to improve the quality and timeliness of information and enhance intra-organizational communication in operational processes. Those involved in mission-critical operations (e.g., hospitals, fire and police departments, army units etc.), for example, might want to invest in improving availability and reliability of the mobile infrastructure since operational errors and delays caused by a lack of ubiquity may lead to serious consequences involving the loss of assets and human lives. Others, whose operations are not mission-critical, can afford to have limited ubiquity- something that is likely to result in lower investments for mobile infrastructures and lower operating expenses. But both types of organizations can potentially achieve a faster and more effective response to new developments in the internal and external environment.

Organizations can also leverage ubiquity to improve services to both internal and external customers. Internal customers may involve the so-called nomadic professionals who need to be supported by information as they travel and perform their duties. Access to information unrestricted by time and space can improve the ability of these professionals to respond to events as they occur in the workplace. Similarly, the ubiquity of mobile technology can help external customers. By providing anytime, anywhere availability, organizations can address questions or concerns related to a purchasing decision on time, on site- leading to higher organizational agility in meeting customer demands and an improved competitive position for the organization. Ubiquity can also be used to form and rearrange partnerships inside and outside of organizational boundaries by rapidly assembling ad-hoc value networks for quickly seizing opportunities in the marketplace. It has the ability to enhance information sharing and communication in these partnerships by removing temporal and spatial constraints.

Third, and lastly, our findings indicate that organizational agility takes place in stages when mobile technology is involved. Operational agility was found to be the most obvious benefit that organizations strive for first by harnessing the accessibility and reachability of mobile technologies and their ability to identify and localize. Once in place, organizations expanded on customer and partnering agility. While this order seems reasonable, it also alludes to the concept that organizational agility cannot be achieved with mobile technology in one go, but has to start with operational processes first. Table 10 summarizes our findings.

Table 10: Achieving organizational agility through mobile technology

\begin{tabular}{|l|l|l|}
\cline { 2 - 3 } \multicolumn{1}{l|}{} & Ubiquity & Uniqueness \\
\hline $\begin{array}{l}\text { Operational } \\
\text { Agility }\end{array}$ & $\begin{array}{l}\text { Improve quality and timeliness of information } \\
\text { and enhance intra-organizational } \\
\text { communication in organizational processes. }\end{array}$ & $\begin{array}{l}\text { Localizing human and non-human } \\
\text { objects to improve quality of decisions, } \\
\text { speed of operations, and overall } \\
\text { effectiveness of an operational unit with } \\
\text { respect to time and space }\end{array}$ \\
\hline $\begin{array}{l}\text { Customer } \\
\text { Agility }\end{array}$ & $\begin{array}{l}\text { Offering on site, on time service to internal and } \\
\text { external customers }\end{array}$ & $\begin{array}{l}\text { Using localization to personalize } \\
\text { products and services offered to } \\
\text { customers }\end{array}$ \\
\hline $\begin{array}{l}\text { Partnering } \\
\text { Agility }\end{array}$ & $\begin{array}{l}\text { Forming and rearranging partnerships inside } \\
\text { and outside of organizational boundaries by } \\
\text { rapidly assembling ad-hoc value networks for } \\
\text { quickly seizing opportunities in the } \\
\text { marketplace }\end{array}$ & $\begin{array}{l}\text { Identifying entities for finding new } \\
\text { opportunities for partnerships }\end{array}$ \\
\hline
\end{tabular}

Future research might want to answer the questions that emerged from this study. This includes identifying optimal levels of ubiquity, for example, along with understanding to what extent ubiquity is important for an organization and which factors contribute to its importance. Also, further in depth study is needed in order to understand the effects of these factors on the level of organizational agility. Likewise, understanding what exactly the factors are that contribute to uniqueness and make it exploitable in its effect on organizational agility is of utmost importance. Overall, we advise future researchers to utilize our findings and quantify each aspect in a measurable manner.

\section{Limitations}

The findings of this study and resulting implications should be viewed in the light of the limitations of this study. The limitations of this study arise from two broad areas: (1) the data sample and (2) the employed data analysis 
methodology. The specific limitations arising from these two areas are discussed in more detail in the two paragraphs below.

A number of limitations can be attributed to the nature of the data set used in this study. The sample of case studies cannot be viewed as representative. First of all, all of the analyzed case studies involved only HP technology and HP clients. This diminishes, to some extent, the external validity of our findings. Secondly, these case studies were largely promotional. While benefits of the mobile technology were thoroughly articulated, virtually none of the studies talked about problems in using mobile technology in organizations. This contributed to a rather unbalanced (overly positive) view with respect to mobile technology. While we acknowledge these limitations, we also believe that they do not diminish the value of the study. Due to the lack of prior theorizing of mobile technology with regards to organizational agility, we feel that our exploratory study can be viewed as an initial thrust towards unraveling the mechanisms at work. Even though limited in its external validity, future studies can benefit from our opening endeavor as it applies, as one of the first in the IS field, to the conceptual framework developed by [37].

Other limitations arise from the inherent weaknesses of the case study method-the research approach employed by this study. First, while being an established research methodology in social sciences [20] and despite attempts to somehow explicate and formalize evaluation criteria towards studies employing this method [18], the case study method does not have a universally accepted set of rigor standards [43]. Moreover, unlike in the case of an experimental setting, case studies are deliberately analyzed within the natural context- something that makes control for confounding variables and influences virtually impossible [3]. All this raises some concerns over replicability of study findings and their generalizability. First, we would like to note that these problems are inherent to the case study method and are counter-balanced by the strength of the case study method-the method's ability to provide rich descriptions and understanding of a phenomenon in its natural setting [43] and to allow for an initial theory building [8]. Second, we tried to mitigate these limitations by providing a detailed account of our research protocol and by employing a multiple-case study approach. We believe that these remedies enhance replicability and generalizability of our findings. Moreover, as it was stated earlier, the main goal of this study is not to confirm a theory but rather to "generalize to a theory" [21]- that is, to provide a preliminary theoretical understanding of how mobile technology can be used to improve organizational agility. Further research along the lines of the additional research questions raised by this study is needed to enhance and confirm the theoretical propositions implicitly formulated as a result of this study.

\section{Conclusion}

Numerous studies on mobile technology have examined the benefits of anywhere, anytime connectivity provided by mobile technologies. However, simple usage of mobile technology as a toy that provides a fun feature of ubiquitous connectivity may not lead to any tangible results in terms of productivity and greater revenues. In order for mobile technology to become a source of competitive advantage, it must be a part of a particular strategic initiative designed for improving the overall competitive position of a company. Business agility may be an appropriate strategic initiative to use mobile technology as its key enabler. This study attempts to show that mobile technology is a good candidate for enhancing organizational agility on the customer, partner, and operational level, and consequently achieving competitive advantage.

\section{Websites List}

Site 1: Hewlett-Packard Development Company, L.P. (HP) http://www.hp.com

\section{References}

[1] M. Alavi and D. E. Leidner, Review: Knowledge management and knowledge management systems: Conceptual foundations and research issues, MIS Quarterly, vol. 25, no. 1, pp. 107-136, 2001.

[2] R. Amit and C. Zott, Value creation in e-business, Strategic Management Journal, vol. 22, no. 6-7, pp. 493-520, 2001.

[3] I. Benbasat, D. K. Goldstein, and M. Mead, The case research strategy in studies of information systems, MIS Quarterly, vol. 11, no. 3, Sept. 1987.

[4] E. Bendoly, A. Bharadwaj and S. Bharadwaj, Complementary drivers of new product development performance: cross-functional coordination, Information System Capability, and Intelligence Quality, Production and Operations Management, vol. 21, no. 4, pp. 653-667, 2012

[5] A. Bharadwaj, O. A. El Sawy, P. A. Pavlou, and N. Venkatraman, Visions and voices on emerging challenges in digital business strategy, MIS Quarterly vol. 37, no. 2, pp. 633-661, 2013.

[6] Q. Cao and S. Dowlatshahi, The impact of alignment between virtual enterprise and information technology on business performance in an agile manufacturing environment, Journal of Operations Management, vol. 23, no. 5, pp. 531-550, 2005.

[7] K. Conboy, Agility from first principles: reconstructing the concept of agility in information systems development, Information Systems Research, vol. 20, no. 3, pp. 329-354, 2009. 
[8] K. M. Eisenhardt, Building theories from case study research, Academy of Management Review, vol. 14, no. 4, pp. 532-550, 1989.

[9] N. D. Evans, Business Agility: Strategies for Gaining Competitive Advantage through Mobile Business Solutions Upper Saddle River. N.J.: Financial Times/Prentice Hall, 2002.

[10] P. Ghemawat, Finding your strategy in the new landscape, Harvard Business Review, vol. 88, no. 3, pp. 54-60, 2010.

[11] S. L. Goldman, R. N. Nagel and K. Preiss, Agile Competitors and Virtual Organizations: Strategies for Enriching the Customer. New York: Van Nostrand Reinhold, 1995.

[12] P. Huang, S. L. Pan and T. H. Ouyang, Developing information processing capability for operational agility: Implications from a Chinese manufacturer, European Journal of Information Systems, vol. 23, no. 4, pp. 462480, 2014.

[13] Intermec Technologies Corporation. (2007) Case Study: METRO Group puts RFID theory into practice, with real word results. [Online]. Available: http://www.intermec.com/public-files/case-studies/en/Metro cs web.pdf

[14] I. A. Junglas and R. T. Watson, Location-based services, Communications of the ACM, vol. 51, no. 3, pp. 65-69. 2008.

[15] I. A. Junglas and R. T. Watson, U-Commerce: A conceptual extension of e-commerce and m-commerce, in Proceedings Twenty-Fourth International Conference on Information Systems, Seattle, Washington, 2003, pp. 576-591.

[16] I. A. Junglas and R. T. Watson, The U-constructs: Four information drives, Communications of the AIS, vol. 17, no. 26, 2006

[17] P. T. Kidd, Agile Manufacturing: Forging New Frontiers. Wokingham, UK: Addison-Wesley, 1994.

[18] H. Klein and M. Myers, A Set of principles for conducting and evaluating interpretive field studies in information systems, MIS Quarterly, vol. 23, no. 1, pp. 67-94, 1999.

[19] V. Krotov and I. A. Junglas, RFID as a disruptive innovation, Journal of Theoretical and Applied Electronic Commerce Research, vol. 3, no. 2, pp. 44-59, 2008.

[20] S. Lee, A scientific methodology for MIS case studies, MIS Quarterly, vol. 13, no. 1, pp. 33-50, 1989.

[21] S. Lee and R. L. Baskerville, Generalizing generalizability in information systems research, Information Systems Research, vol. 14, no. 3, pp. 221-243, 2003.

[22] G. Lee and W. D. Xia, Toward Agile: An integrated analysis of quantitative and qualitative field data on software development agility, MIS Quarterly, vol. 34, no. 1, pp. 87-114, 2010.

[23] Q. Li, R. N. Nagel and L. Sun, Migrating to agility 2.0: How social computing creates strategic value, Organizational Dynamics, vol. 40, no. 2, 119-126, 2011

[24] L. Lindstrom and R. Jeffries, Extreme programming and agile software development methodologies, Information Systems Management, vol. 21, no. 3, pp. 41-52, 2004.

[25] E. J. Lowe, A Survey of Metaphysics. Oxford: Oxford University Press, 2002.

[26] M. Lu and J. H. Song, Key design factors for extra-organizational systems, International Journal of Information Management, vol. 7, no. 3, pp. 159-166, 1997.

[27] Y. Lu and K. Ramamurthy, Understanding the link between information technology capability and organizational agility: An empirical examination, MIS Quarterly, vol. 35, no. 4, pp. 931-954, 2011

[28] L. Mathiassen and J. Pries-Heje, Business agility and diffusion of information technology, European Journal of Information Systems, vol. 15, no. 2, pp. 116-119, 2006

[29] N. B. Mavengere, Role of information systems for strategic agility in supply chain setting: Telecommunication industry study, The Electronic Journal of Information Systems Evaluation, vol. 17, no. 1, pp 100-112, 2014

[30] R. N. Nagel and R. Dove, 21st Century Manufacturing Enterprise Strategy: An Industry-Led View. Bethlehem, PA: DIANE Publishing, 1991.

[31] S. Nazir and A. Pinsonneault, IT and firm Aaility: An electronic integration perspective, Journal of the Association for Information Systems, vol. 13, no. 3, p. 2, 2012.

[32] S. Nerur, R. Mahapatra and G. Mangalaraj, Challenges of emigrating to agile methodologies, Communications of the ACM, vol. 48, no. 5, pp. 72-78, 2005.

[33] E. Overby, A. Bharadwaj and V. Sambamurthy, A framework for enterprise agility and the enabling role of digital options, in Business Agility and Information Technology Diffusion (R. L. Baskerville, L. Mathiassen, J. Pries-Heje, and J. DeGross, Eds.). New York: Springer US, 2005, pp. 295-312.

[34] G. Piccoli and B. Ives, Review: It-dependent strategic initiatives and sustained competitive advantage: A review and synthesis of the literature, MIS Quarterly, vol. 29, no. 4, pp. 747-776, 2005.

[35] A. Rai, P. A. Pavlou, G. Im, and S. Du, Interfirm IT capability profiles and communications for cocreating relational value: Evidence from the logistics industry, MIS Quarterly, vol. 36, no. 1, pp. 233-262, 2012.

[36] N. Roberts and V. Grover, Leveraging information technology infrastructure to facilitate a firm's customer agility and competitive activity: An empirical investigation, Journal of Management Information Systems, vol. 28, no. 4, pp. 231-270, 2012.

[37] V. Sambamurthy, A. Bharadwaj and V. Grover, Shaping agility through digital options: Reconceptualizing the role of information technology in contemporary firms, MIS Quarterly, vol. 27, no. 2, pp. 237-263, 2003.

[38] N. N. Taleb, Antifragile: things that gain from disorder. USA: Random House Digital, Inc., 2012.

[39] P. P. Tallon and A. Pinsonneault, Competing perspectives on the link between strategic information technology alignment and organizational agility: insights from a mediation model, MIS Quarterly, vol. 35, no. 2, pp. 463-484 2011.

[40] D. J. Teece, Explicating dynamic capabilities: The nature and microfoundations of (sustainable) enterprise performance, Strategic Management Journal, vol. 28, no. 13, pp. 1319-1350, 2007. 
[41] P. Weill, M. Subramani and M. Broadbent, Building IT infrastructure for strategic agility, MIT Sloan Management Review, vol. 44, no. 1, pp. 57-65, 2002.

[42] H. Yang, S. L. Huff and M. Tate, Managing the cloud for information systems agility, in Cloud Computing Service and Deployment Models: Layers and Management (A. Bento and A. K. Aggarwal Eds.). Hershey, PA: IGI Global, 2013, pp. 70-93.

[43] R. K. Yin, Case Study Research: Design and Methods, 3rd ed. Thousand Oaks. CA.: Sage Publications, 2003.

[44] Z. Zhang and $\mathrm{H}$. Sharifi, A methodology for achieving agility in manufacturing organisations, International Journal of Operations \& Production Management, vol. 20, no. 4, pp. 496-513, 2000. 